\title{
The digestive system of xenacoelomorphs
}

\author{
B. Gavilán ${ }^{1}$ - S. G. Sprecher ${ }^{2}$ - V. Hartenstein ${ }^{3} \cdot$ P. Martinez ${ }^{1,4} \oplus$
}

\begin{abstract}
Interest in the study of Xenacoelomorpha has recently been revived due to realization of its key phylogenetic position as the putative sister group of the remaining Bilateria. Phylogenomic studies have attracted the attention of researchers interested in the evolution of animals and the origin of novelties. However, it is clear that a proper understanding of novelties can only be gained in the context of thorough descriptions of the anatomy of the different members of this phylum. A considerable literature, based mainly on conventional histological techniques, describes different aspects of xenacoelomorphs' tissue architecture. However, the focus has been somewhat uneven; some tissues, such as the neuro-muscular system, are relatively well described in most groups, whereas others, including the digestive system, are only poorly understood. Our lack of knowledge of the xenacoelomorph digestive system is exacerbated by the assumption that, at least in Acoela, which possess a syncytial gut, the digestive system is a derived and specialized tissue with little bearing on what is observed in other bilaterian animals. Here, we try to remedy this lack of attention by revisiting the different studies of the xenacoelomorph digestive system, and we discuss the diversity present in the light of new evolutionary knowledge.
\end{abstract}

Keywords Xenacoelomorpha - Xenoturbella $\cdot$ Nemertodermatida $\cdot$ Acoela $\cdot$ Digestive system $\cdot$ Syncytium $\cdot$ Lumen . Ultrastructure

\section{Introduction}

Xenacoelomorphs have become a group of animals that is central to many debates of the evolutionary origin of Bilateria. Though relatively unknown, their key position as the sister group of the remaining bilaterians suggests they have intrinsic value as putative proxies for the origin of many bilaterian novelties; see Baguñà and Riutort (2004) and Hejnol and Pang (2016). It is important to state, though, that

V. Hartenstein

volkerh@mcdb.ucla.edu

$\bowtie$ P. Martinez

Pedro.martinez@ub.edu

1 Departament de Genètica, Microbiologia i Estadística, Universitat de Barcelona, Av. Diagonal 643, 08028 Barcelona, Spain

2 Department of Biology, University of Fribourg, 10, ch. Du Musée, 1700 Fribourg, Switzerland

3 Department of Biology, University of California, Los Angeles, CA, USA

4 Institut Català de Recerca i Estudis Avançats (ICREA), Barcelona, Spain this is not a complete consensus since some researchers have suggested an alternative view of xenacoelomorphs as the most basal deuterostomian clade (Philippe et al. 2011). While most molecular phylogenies agree on the monophyly of xenacoelomorpha (i.e., Philippe et al. 2011), there is still some incongruence in the morphology (such as in the spermatozoa) that challenges this view (see Buckland-Nicks et al. 2018).

Xenacoelomorpha is composed of three major clades: Acoela, Nemertodermatida and Xenoturbellida. The first two constitute Acoelomorpha, the sister clade of Xenoturbellida. The majority of species in this phylum are marine animals and of all the nominal species recognized today, more than $90 \%$ belong to Acoela. Nemertodermatida and Xenoturbellida are represented by only a few species, though there are many others recognized as cryptic and probably inhabitants of unexplored habitats (Meyer-Wachsmuth et al. 2014; Arroyo et al. 2016). Xenacoelomorphs have always been considered as having a "simple" morphology (Achatz et al. 2013; Hejnol 2015). They are all characterized by the presence of a single digestive opening, located at different positions along the major body axis, with ciliated epithelia and they are innervated by a basiepidermal net of neurons, which are in most cases, condensed, to different 
degrees, at the anterior end of the animal (Achatz and Martinez 2012; Martinez et al. 2017). The nervous system includes a statocyst at the frontal end plus, in some cases, a pair of eyespots. Xenacoelomorphs move by gliding in sand and mud substrates, using their epidermal cilia. A film of mucus produced by scattered ventral glands helps locomotion. Muscles are preferentially organized as bands of circular, longitudinal and oblique fibers. Additionally, dorsoventral muscles are prevalent in most animals (Semmler et al. 2008; Børve and Hejnol 2014). Many acoels are able to regenerate different body parts (Perea-Atienza et al. 2013; Srivastava et al. 2014) and some of them use regeneration as a reproductive strategy (Sikes and Bely 2008). Similar capacities are not known in xenoturbellids and nemertodermatids.

\section{General characteristics of the xenacoelomorph digestive systems}

The digestive system (originally named "central parenchyma") of xenacoelomorphs, which is a sack-like gut, has been regarded as peculiar in terms of its ultrastructure and cellular composition. The assumed phylogenetic position of this phylum as the sister group of the remaining bilaterians has prompted some authors to consider that this peculiar architecture could represent an ancestral condition for bilateria. This is consistent with the overall organization of the Xenoturbellida gut: a simple epithelial gut with a single opening and a central empty cavity. However, Acoelomorpha present different arrangements of cells and the progressive loss of a central cavity in favor of a consolidated central syncytium of digestive cells, which is definitely a derived condition within the phylum. In fact, the syncytial state of the central parenchyma in Acoela has been regarded as a specialization corresponding to the intracellular digestion of food items that are too large to be digested intracellularly in a single cell (Mamkaev and Seravin 1963; Kozloff 1972).

As with many other anatomical structures (i.e., position of the mouth, arrangement of muscles and neural components and the copulatory organs; see Achatz et al. (2013), the structure of the digestive system in Xenacoelomorpha presents considerable variation, a feature that some consider a reflection of plesiomorphy [called the "Mamkaev principle" (Mamkaev 1986), by Haszprunar (Haszprunar 2015)]. As mentioned above, Xenoturbellida and Nemertodermatida have cellular, epithelial guts (Fig. 1). However, where the plastic nature of the digestive system is most clear is within the Acoela. Here, one can distinguish at least four different structural arrangements that could be defined as (see also Fig. 2): (1) permanent central syncytium enclosed by wrapping cells - most acoels, especially Convolutidae but also Diopisthoporus sp. (Smith 1981); (2) lacking syncytial structures, intracellular digestion-Paratomella rubra (Ehlers 1992b); (3) central lumen with temporary syncytial structures along the walls (defined as necrotic digestion by O. Raikova) Actinoposthia beklemischevi (Raikova 1987); (4) central lumen and permanent syncytial structures along the wallsHofsteniidae, Haploposthia opisthorchis, Aphanostoma virescens and Paedomecynostomum (Smith 1981). Interestingly, in some families, species with lumen and others with syncytium can be detected, suggesting even greater flexibility in the organization of these digestive systems.

The cellular organization of the different members of Xenacoelomorpha has been studied but in this case, we have few extensive, ultrastructural data except for those relating to some acoels. In Xenoturbellida, the cells in the digestive epithelium were initially described as syncytial (Westblad 1949b); though, in more recent papers (Israelsson 1999, 2006), the gut lining is described as a gastrodermis with individuated cells, organized as an epithelia. Within the gastrodermis, there are numerous small granular glands. In members of the Nemertodermatida, the intestine seems to be formed of two different cell types: the so-called amoeboid and gland cells (traditionally called "Körnerkolben" auctorem, or mucous cells).

In the syncytial acoels (most of the species described to date), two major cell types seem to be present: the cellular mass that constitutes the central syncytium and the surrounding, wrapping cells. There are two (e.g., Diopisthoporus c.f. longitubus) or three (e.g., Convoluta convoluta) types of wrapping cells reported. The distribution of these cells seems to vary among species. Recently and in the case of I. pulchra, an excretory function for some of these cells has been suggested.

There are a few other cases where further specialization of the gut is observed (e.g., Actinoposthia beklemischevi) where the arrangement and types of cells seem slightly different, with the presence of necrotic fragments contributing to the histology of the central tissue.

The diversity and peculiarity of the different xenacoelomorph digestive systems are described in more detail in the next sections.

\section{The digestive system of Xenoturbellida}

Xenoturbellida is represented by a small number of marine species, mostly living at considerable depths: from 50 to $2500 \mathrm{~m}$ below the marine surface. We only have reliable data on the digestive system for one species, Xenoturbella bocki, in the work of Einar Westblad (Westblad 1949b). In the classical description of this species, Westblad states that the mouth orifice is small and only visible on sectioned specimens; a statement corroborated by recent observations by Nakano (cited in Bourlat et al. 2008), which specifies the size of this opening as 1-2 mm. A true pharynx, containing elements, such as additional muscle layers or sphincters of parenchymal origin, is lacking in Xenoturbella (see Riedl 1954 for 
definitions and Todt 2009 for a critical view). The lining of the intestine is epithelial and is clearly differentiated from the overlying parenchyma and the gut lumen. The gastric cavity is surrounded by circular muscles, muscles that are weakly stained with phalloidin (Raikova et al. 2000). They are connected to the body wall through a set of loose inner radial muscles (Fig. 1a, b). The gastrodermis is composed of a single, uniform layer of tall, elongated cells that bear numerous small intracellular inclusions with basophilic granulated content (phagocytic vesicles). These cells have no cilia. In mature females, during the mating season, the gastrodermis bears some canals (Israelsson 1999) of unknown function. In the gastrodermis, Israelsson (2007) revealed the presence of numerous chlamydiae symbionts, without any cytopathological effects, and Kjeldsen and collaborators (Kjeldsen et al. 2010) found also abundant Gammaproteobacteria. These symbionts are not present in other tissues of the animal. Whether they contribute to the digestive function or not, it is an issue that remains unexplored. Very little else has been described in other xenoturbellids. The presence of gastrodermal cells with glandular inclusions was noticed, using histological sections, in Xenoturbella profunda by Rouse and collaborators (Rouse et al. 2016). However, as observed in Westblad's original description, the histology of the parenchymal layer is hard to investigate due to difficulties in obtaining good tissue preservation (our own observations, see for instance, the central area in Fig. 1b).
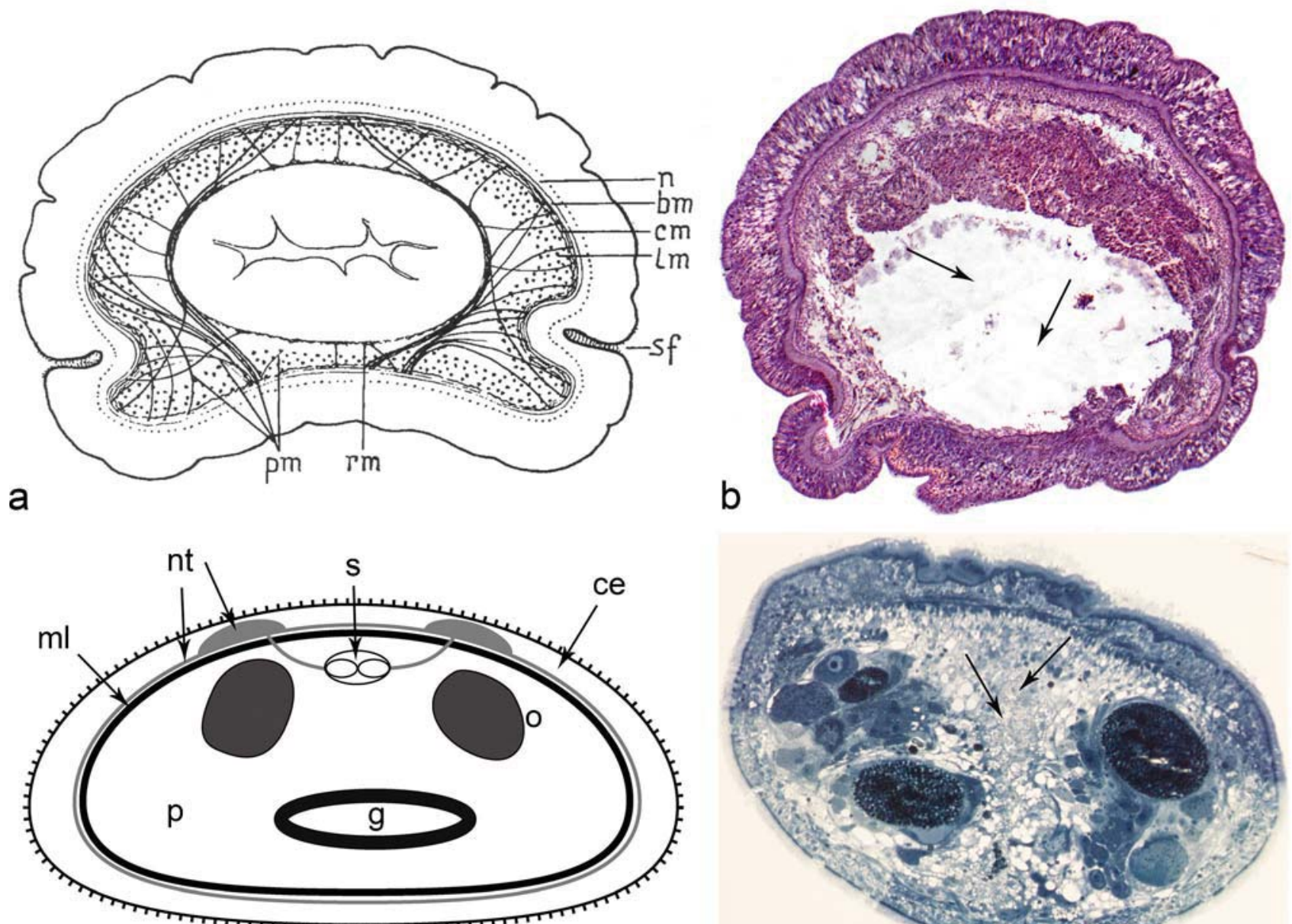

C

Fig. 1 Microscopic anatomy of the xenoturbellid's and nemerdoermatid's digestive tracts (dorsal to the top). a Transversal section through the body of Xenoturbella bocki (from Westblad 1949b). Central, white, region corresponds to the intestine. Pm and $\mathrm{rm}$. are peripheral and reticular muscles. b Eight-micron, transversal section, of Xenoturbella bocki stained with hematoxylin and eosin. The central, whitish, region is occupied by the gut lumen (arrows). c General diagram of the nemertodermatid gut (scheme derived from histological sections of Meara stichopi: modified from Hejnol 2016); the central lumen, in spite of the appearance in the diagram, is normally occluded. Light gray circle

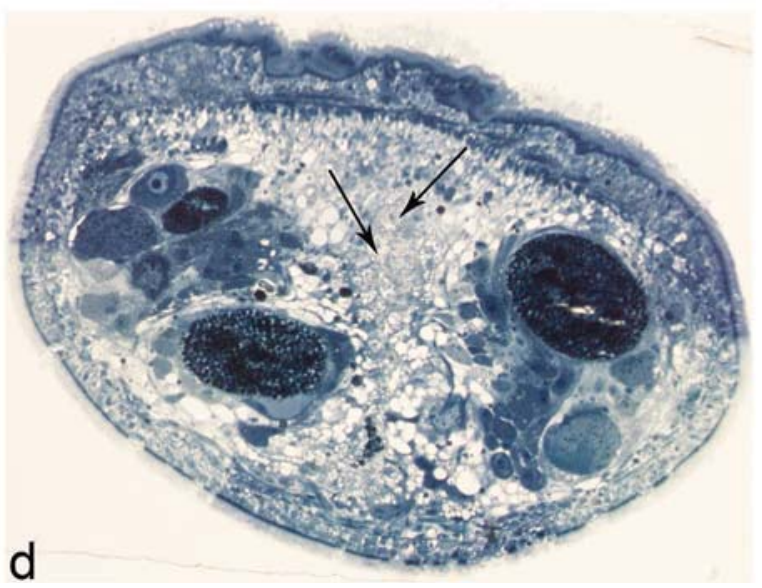

marks nervous tissue and black circle marks the muscle. d One-micron section of Meara stichopi (Nemertodermatida) stained with $1 \%$ toluidine blue and processed for microscopy as in Buckland-Nicks et al. (2018) (picture supplied by Dr. John Buckland-Nicks). The side of the body with the seemingly thicker epidermis is the dorsal side (upwards in the picture). The central gray area is the gut (arrows), with a diverticulum of the gut reaching downward, towards the ventral side. On the sides of the gut there are testes and ovaries. CE, ciliated epithelium; G, intestine (with diverticula); ML, muscle layer; NT, neural tissue; Oo, oocytes; P, parenchyma; S, statocyst 


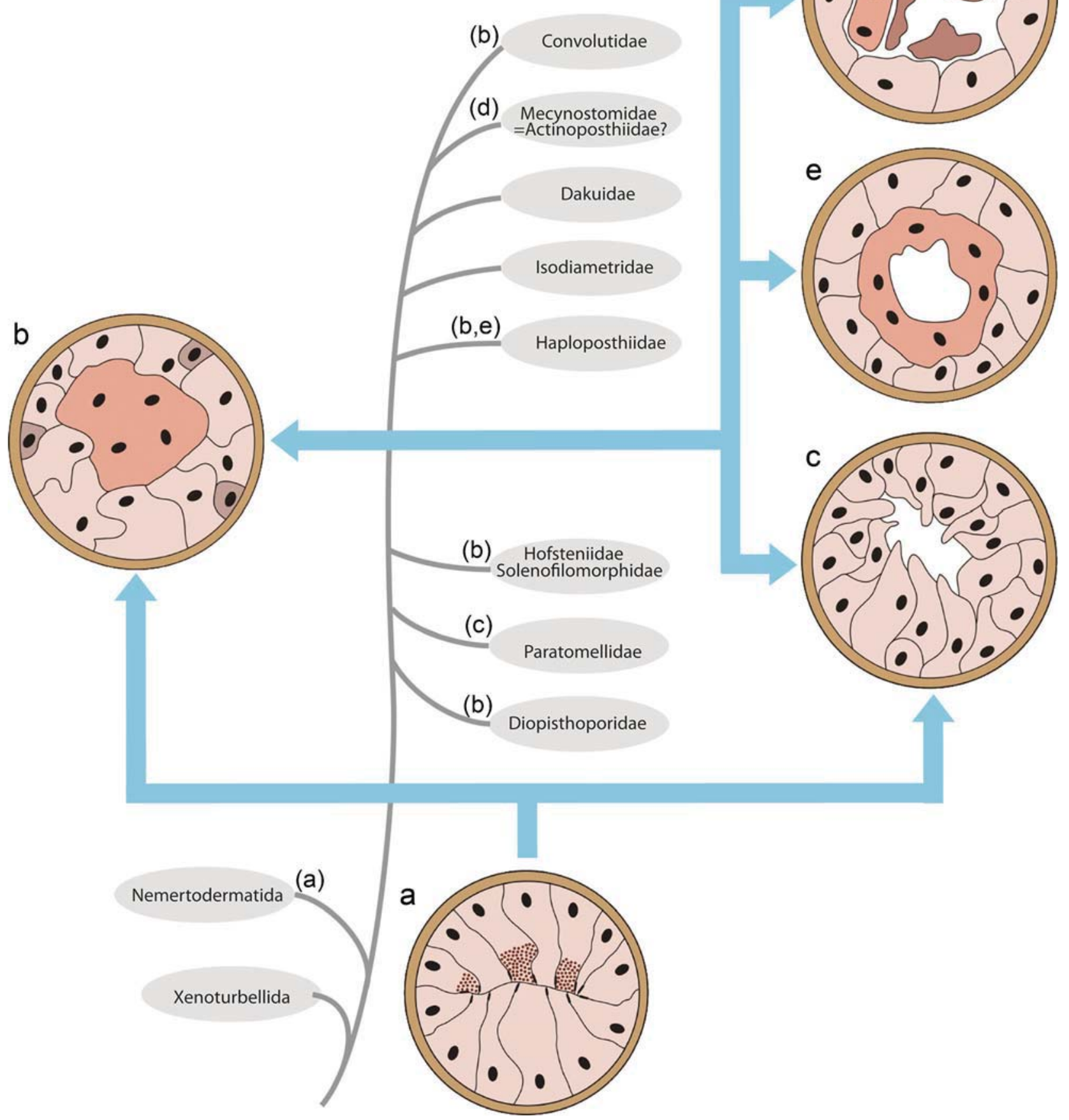

The process of digestion in Xenoturbella is not well understood. Westblad gives a very superficial report of what might happen when these animals are fed. He addressed digestion through an indirect way, discussing the implications of the anatomy of the system. In particular, he stresses that the folding of the epithelium at the mouth leads to a ciliated pseudopharynx (a real pharynx is lacking). Since the

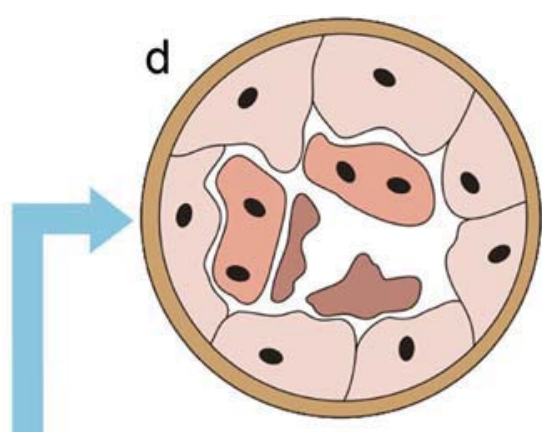

pharyngeal muscles are lacking, probably the movements of gulping are slow, implying that this animal cannot be a rapacious creature. Westblad never found any diatoms or small animals in the intestine thus proposing that Xenoturbella must feed on "decomposed fragments of dead animals in the mud". He observes, though, that the thickness of the intestinal epithelium (full of glands) increases in well-fed animals. 
Fig. 2 Diversity of digestive tract architectures in the Xenacoelomorpha (diagrams modified from Smith and Tyler 1985). The center of the diagram shows a phylogenetic tree of the phylum (based on Jondelius et al. 2011). Grouped around the tree are schematic cross-sections that illustrate the basic types of intestinal structure encountered in the xenacoelomorphs. A gut lined by epithelial cells, observed in xenoturbellids and nemertodermatids (a), is thought to be the primitive state. The digestive syncytium (b; red), encountered in most acoels (both basally branching and derived), could have evolved from the cellular epithelial gut (blue arrow at bottom, left). Surrounding the syncytium is the peripheral parenchyma (light brown). Some basal acoels (e.g., Paratomella rubra) possess a cellular mesenchymal gut (c) that could also be derived from an epithelial gut (bottom arrow, right). Another variant of acoel gut structure is a central lumen surrounded by a digestive syncytium that can be temporary, as in Actinoposthia beklemischevi (Actinoposthiidae; e) or permanent, as shown for Kuma flava (Haploposthiidae; (d). Given the sporadic occurrence of these gut phenotypes along the phylogenetic tree it is likely that they could have evolved from the canonical digestive syncytium lacking a lumen, or from a mesenchymal gut type as seen in Paratomella (multi-headed blue arrow at top of diagram). The fact that different families have species with a particular gut structure does not mean that ALL members of the family share the same organization. Data come from the few species well studied

A recent molecular barcoding analysis (Bourlat et al. 2008) suggested that Xenoturbella bocki is a specialist feeder, selecting bivalve prey as its main source of food. Given the small size of the Xenoturbella bocki's mouth, it is unlikely that they feed on adult bivalves; they most probably ingest decaying mollusks or any mollusk components such as egg masses, sperm, larvae or slime. The habitats of other xenoturbellids are very varied and include locations such as sediments near hydrothermal vents (Rouse et al. 2016), suggesting the possibility of different feeding habits. The different papers characterizing new xenoturbellid species do not address the question of intracellular vs. extracellular digestion. Interestingly, the analysis of the $X$. bocki's genome (P.M.; unpublished data) revealed the presence of homologs of some genes encoding for digestive enzymes (i.e., carboxypeptidase, trypsinogen, or gastric lipase).

\section{The digestive system of Nemertodermatida}

Nemertodermatida is represented today by 18 nominal species but there is evidence of further, as of yet undescribed, species (Meyer-Wachsmuth et al. 2014). However, current knowledge of the structure and physiology of the digestive system is derived from very few species (Meara stichopi (i.e., Fig. 1c, d), Nemertoderma westbladi, Flagellophora apelti and Nemertinoides elongates).

The intestine of nemertodermatids is epithelial, as in xenoturbellids but different from the syncytial form observed in most acoels. In fact, early literature concentrated on the controversy over the cellular vs. syncytial nature of the gut, plus the presence of an empty lumen, not always easy to visualize. Originally, the work of Steinböck (1930) and
Westblad (1949a) suggested that the intestine of these animals, as in acoels, was syncytial. Karling finally resolved the controversy in 1967 (Karling 1967) by reanalyzing Westblad's slides. The extensive ultrastructural work of Tyler and Rieger (1977), using electron microscopy suggested some reasons for the controversy, mainly derived from the presence of large interdigitating cells in the gut epithelium and the use of semithin sections. In fact, Tyler and Rieger showed that the degree of interdigitation of these cells is so great that the cell borders were impossible to distinguish using light microscopy. It is now generally accepted that the digestive tract is lined by an epithelial layer composed of phagocytes (amoeboid cells) and gland cells (Smith 1981). The size of the lumen, described as an "irregular space where cell processes of the intestine interdigitate" (Tyler and Rieger 1977) is variable in species analyzed to date. In some nemertodermatids, the digestive lumen is obscured by the presence of these interdigitating processes (Karling 1974). Cell contacts are characterized by the presence of septate and adherens junctions (Tyler and Rieger 1977). Riser, who investigated the presence of cilia projecting into the lumen of the gut in Nemertinoides, was unable to find them, speculating that if they are present, they are probably widely scattered. In general, it is assumed that in nemertodermatids, ciliation in the gastrodermis is absent. However, Karling (1967) stated that in the genus Nemertoderma, the gut is partially ciliated. However, Karling observed, in light microscopy, the remains of worn epidermal multiciliated cells withdrawn to the gastrodermis to be digested (the so-called flamed cells in older literature). In this context, it is worth mentioning the re-evaluation of the fate of epidermal cells in different xenacoelomorphs done by Lundin and Hendelberg (1996) and Lundin (2001) that contradicts the interpretations of Karling. Tyler and Rieger (1977) also showed, by TEM, the presence of cellular remains inside the gut of a nemertodermatids, in this case, a single flagellum, which could have been the tail of an ingested allosperm. These different observations leave the subject of the gut ciliation as still unresolved.

Two different types of gastrodermal cells, amoeboid cells and gland cells ("Körnerkolben" auctorem or mucous cells), have been described for Nemertodermatids. Gland cells are well described in the dorsal wall of the gut, immediately above the pharynx, for Nemertinoides elongates (Riser 1987) and for Flagellophora apelti, where these cells contain stained cyanophil granules and large nuclei, suggesting intense secretory activity (Faubel and Dörjes 1978). For Meara stichopi, a typical gland cell is characterized as "broad in its basal part and conically sharpened at its distal end" (Westblad 1949a). While Riser states that most of the glandular cells are located in the dorsal wall of the gut in Nemertinoides, Westblad suggests that in Nemertoderma and Meara, it is very rare or impossible to find these cells in this dorsal location. According to 
Faubel and Dörjes, the "Körnerkolben" cells secrete mucus into the gut's lumen.

The amoeboid (also referred to as phagocytic) cells were described thoroughly by Westblad (Westblad 1949a). Their nuclei are small and occupy different positions in the epithelium. These cells often project into the intestine and in their distal end and they tend to contain small accumulations of dark grains, probably excrement particles (better, residual bodies). Often, at least in Meara, sperm and spermatocyte cells are present in these cells, an example of the use of these cells for resorbing germinal cells by the intestine. Westblad therefore speculated that these cells might play an assimilatory and excretory role. In addition, these cells contain mitochondria, lipid droplets, lysosomes and small vesicles with flocculent contents (Smith 1981) The presence of numerous phagosomes within the phagocytes indicates that the digestion in Nemertoderma is, at least in part, intracellular (Tyler and Rieger 1977; Smith 1981).

Little is known about the feeding activities of Nemertodermatida. They seem to be omnivorous, living on diatom algae and small invertebrates. Sterrer (1998) and Westblad (1949a) speculated on the putative feeding mechanisms, mainly through the interpretation of histological observations of Nemertoderma and Meara. In both cases, an embankment of cells resembling lips surrounds the mouth (only visible in immature specimens of Nemertoderma). In the area of the mouth, the musculature is quite different for the two species. While in Nemertoderma, there are no muscles specifically associated with the structure (which seems just an opening through the body wall), in Meara ventrolateral muscles bend around the mouth, posteriorly, forming a thick lip (Meyer-Wachsmuth et al. 2013). Westblad proposed that the ingestion of food could be the result of a lip formation and the direct sucking in of food particles. In the specific case of Meara, Westblad observed diatoms and copepods filling the intestine. Wolfgang Sterrer also observed the presence of a nematode (Sterrer 1998). No other observations of the feeding habits are known for nemertodermatids.

A new excretory function associated with the gut in Nemertodermatida has recently been uncovered by Andrikou and collaborators (Andrikou et al., n.d.). These investigators showed that both "excretion-related" (associated with different morphological domains within the nephridia, i.e., rootletin, solute carrier transporters or aquaporins) and genes involved in the excretion of ammonia (i.e., Rhesus, $\mathrm{Na}+\mathrm{K}+$ ATPase, or carbonic anhydrase) are expressed in different domains of the M. stichopi gut. Moreover, the functional analysis of different components of the ammoniaexcretion system corroborates the presence of an active excretion process in the nemertodermatids (and also in acoels, see below).

\section{The digestive system of Acoela: overview and nomenclature}

With around 400 known species, the clade Acoela is the best described within Xenacoelomorpha. Moreover, a solid internal phylogeny, resulting from molecular and morphological characters, provides us with an evolutionary framework to interpret the cellular architecture in this group (Jondelius et al. 2011). With this framework in mind, we will describe the pertinent features of the Acoel digestive systems (see as a guide Fig. 2).

Most acoels lack an epithelial gut. Instead, they possess a syncytial mass called "central syncytium" (Smith and Tyler 1985), "digestive syncytium" (Mamkaev and Seravin 1963), "central parenchyma" (Pedersen 1964), or "endocytium" (Westblad 1940). Surrounding the central syncytium is a zone of cellular elements, called the "peripheral parenchyma" (Pedersen 1964) or "ectocytium" (Westblad 1940). The number and morphology of these cellular elements is variable between species. A morphologically distinct border such as a basal lamina does not separate these two domains. The central parenchyma is histologically distinguished from the peripheral parenchyma by its lower density of nuclei and high abundance of vacuoles, which were interpreted as "phagocytic vacuoles" (i.e., phagosomes and lysosomes). These phagocyte-like characteristics of the central parenchyma are reflective of its function as the organ for nutrient absorption and intracellular digestion (Pedersen 1964) Interestingly, in some cases, e.g., Paedomecynostomum sp. (Mecynostomidae) and Philactinoposthia sp. (Dakuidae), the syncytium is only transiently formed after ingestion of food and is shed when digestion is complete, leaving a large central cavity (Mamkaev and Markosova 1982; Smith 1981).

Digestion may not be the only function of the central parenchyma. The above discussed recent data by Andrikou and collaborators (Andrikou et al. n.d.), using a large cohort of marker genes, shows that the digestive/central parenchyma may also be involved in excretion: a primitive role that predates the origin of specialized secretory tissues such as nephridia in the Nephrozoa. The syncytial nature of the central parenchyma was, for some time, a matter of intense debate. Thus, the first ultrastructural studies of acoels, by Pedersen (1964) and Dorey (1965), contested the old notion that acoel digestive tissues were only syncytial (i.e., Steinböck 1930). Subsequent years saw a new series of studies such as those by Klima (1967), Kozloff (1972) and Mamkaev in different collaborations (Ivanov and Mamkaev 1977), showing that a good part of, if not all, the central parenchyma was indeed syncytial in many acoels. It was Mamkaev in 1967 (Mamkaev 1967) who, when revising the electron micrographs of Pedersen, observed that they were not entirely convincing. He pointed to the fact that the structures that Pedersen interprets as cell membranes could in fact be interpreted as 
fixation artifacts. This debate seems to have been settled now but see our section on Symsagittifera roscoffensis for a more nuanced reappraisal of this issue.

In the following sections, we will describe the microscopic anatomy of the best-described acoels, following the arrangement of clades suggested in the phylogenetic study of Jondelius and collaborators (Jondelius et al. 2011) starting at deeper nodes and moving progressively to more recent ones. To simplify the description, our clades here will refer, in general, to families.

\section{Early branching Acoels: Diopisthoporidae, Paratomellidae and Hofsteniidae}

The oldest diverging clade within Acoela (Jondelius et al. 2011) is the Diopisthoporidae (Fig. 2). Very little is known about the structural organization of the digestive system in this family, except in the species Diopisthoporus c.f. longitubus, in which it has been noted that the gut contains a central syncytium surrounded by two types of parenchymal (wrapping) cells, named simply p1 and p2 by Smith (1981). The two types of parenchymal cells have the following characteristics. Type 1 cells are voluminous, extend from the body wall to the syncytium and have broad processes that interdigitate with other cells of the body wall and with other type 1 cells. Type 2 cells are smaller, have contacts with body wall cells and type 1 parenchymal cells but do not reach the syncytium (Smith 1981). A membrane bounds the central syncytium, which is in direct contact with the membrane of the type 2 cells. The nuclei in the syncytium are not distributed homogenously, have a mostly elongated shape and contain nucleoli. No syncytium is detected in the area of the pharynx. Smith (1981) also suggested that in D. longitubus, one of the two types of wrapping cells may be stem cells in charge of replacing the lost cells of the other type (an argument based on the presence of a similar centriolar bundle); the latter will, eventually, fuse with the syncytium. In fact, the internal organization of type 2 cells is similar to that seen in the neoblasts of the triclads (platyhelminthes). However, Smith alerts us of the presence of many differences between these cell types and tells us that the evidence in Diophistoporus is only that type 2 cells may replace type 1 ; very different from the totipotent nature of the triclad neoblasts. It could very well be that type 2 cells are just the progenitors of type 1 .

Very little is known about the diversity of the digestive systems in the Paratomellidae and most of our knowledge comes from the study of the Paratomella species (in particular P. rubra; see Ehlers 1992b). The few species of the taxon Paratomella show several characteristics that would be unusual in most other acoels, among them the presence of asexual reproduction through paratomy, a complex glandular system in the periphery of the body; caudal haptocilia, a complex frontal glandular system; and a statocyst without a capsule. The genus Paratomella lacks a proper "peripheral parenchyma" without a digestive function. Another remarkable feature of the taxon Paratomella is the presence of a cellular digestive system, a peculiarity not shared by all paratomellids (see below). Ehlers (1992a, b), who described the ultrastructure of Paratomella rubra tissues for the first time, observed that the digestive system is not syncytial (a difference with most other acoels) but consists of a solid mass of mesenchymal cells with the hallmarks of phagocytes. These cells extend many processes into extracellular fluid-filled spaces. Surrounding a central mass of digestive phagocytes are other cells called "peripheral digestive parenchyma" by Ehlers (1992a, b). Peripheral cells, many of which also show ultrastructural features of phagocytes, send projections into the central area where they intermingle with the processes of central cells. Ehlers suggests the possibility that these cells correspond to the wrapping cells of other acoels. Gland cells are absent.

The peripheral (digestive) parenchymal domain also contains stem cells and digestive cells that appear less differentiated, supporting the notion that, similar to other acoels, the peripheral domain adds new cells that then replace central phagocytes lost to wear and tear. This assertion indicates the possibility that his "peripheral, digestive, parenchyma" areas might contain elements of what are known as peripheral and central parenchyma in other acoel taxa: the differences might just be a matter of nomenclature. Digestion in Paratomella seems to follow a combined extracellular and intracellular pathway, whereby the inner digestive cells break down, thereby emptying their enzymatic content into the lumen (holocrine secretion). Remaining cells absorb the partially digested nutrients and further process it by intracellular digestion.

Another specificity of Paratomella (family Paratomellidae) digestive cells is their association with a highly modified epithelial cell, most probably with an excretory function, which Ehlers (1992a) calls dermonephridia (see above).

Interestingly, it may well be that the cellular organization of the digestive tract of P. rubra is not a general feature of the Paratomellidae, given that a different species, Hesiolicium inops, seem to possess a central syncytium with wrapping cells (Crezée and Tyler 1976). In absence of any other described member of the Paratomellidae, it is difficult to speculate on what is the ancestral condition of the digestive system for this family.

Members of the Hofsteniidae (Papi 1957; Beltagi and Mandura 1991) bear a syncytial gut without an epithelial lining. This central parenchyma has large vacuoles and few nuclei. Corrêa (1960) described the nowadays well-studied species Hofstenia miamia. He provide a short description of the gut: a syncytium enclosing several vacuoles but with no obvious intestinal cavity. Other, more recent, papers emphasize the syncytial nature of the gut but, besides describing the 
general appearance of semithin histological sections (Hooge et al. 2007), do not give more ultrastructural details.

\section{Recent lineages of the Acoela (class Crucimusculata): Isodiametridae and Convolutidae}

Kozloff (1972) analyzed, for the first time, the digestive processes occurring in a member of the Isodiametridae family: Otocelis luteola. He demonstrated, using electron micrographs, that the digestive tissue has an "alveolar" (vacuolated) character, with no evidence for cell membranes. Nuclei are sparse and widely separated and the cytoplasm between the alveoli is rich in mitochondria. Interestingly, Kozloff demonstrated that treatment with nickel induces extrusion of the digestive tissue (Mamkaev and Seravin 1963 observed a similar effect in Convoluta) and this mass, with no trace of cellularity, can be maintained in seawater for several hours, while it actively digests whatever it was inside at the time of extrusion. A hyaline layer that Kozloff assumes to be similar to "the ectoplasm of certain amoeba" surrounds the digestive mass. Kozloff (1972) told us that food (diatoms) is found, soon after being ingested through the mouth, located within vacuoles in the syncytium. The vacuoles tend to move inside it while digestion proceeds. The empty frustules (diatom shells) accumulated in vacuoles are later extruded through the mouth in defecation. This prompted Smith (1981) to suggest that $O$. luteola feeds by phagocytosis and defecates by exocytosis. A similar observation by Smith (1981) on Kuma $s p$. led to the suggestion that the central syncytium has the capabilities of a large digestive phagocyte, with the digestion being of an "intracellular" mode (intrasyncytial). In a different member of the Isodiametridae (I. pulchra), it has been shown that the expression of genes "excretion-related" and genes involved in the excretion of ammonia are expressed in different domains of the gut. This pattern is shared with the nemertodermatid $M$. stichopi, corroborating the presence of an active excretion process in the acoelomorphs. Interestingly, one of those genes involved in ammonium secretion, Rhesus, is expressed in cells lining the central syncytium of I. pulchra, cells that are, by position and morphology, most probably the wrapping cells.

It is mainly through the study of members of the most highly derived family, Convolutidae, that we have gained a better understanding of the ultrastructure and the feeding modes of acoels. The studies of Jennings (1957); Mamkaev and Seravin (1963); Pedersen (1964); Mamkaev (1967); Smith (1981); Markosova (1976) and Drobysheva (1986) have all proved particularly useful in revealing the details of the structure and function of convolutid digestive systems.

Jennings (1957) and Mamkaev and Seravin (1963) observed that large prey (diatoms or crustaceans) are grasped by the anterior end of the body and pushed, by means of strong contractions of the body, through the extensible mouth into the digestive syncytium. In contrast, small particles are driven through the mouth by ciliary currents, sink into the digestive tissue and are absorbed by phagocytosis. A detailed study of the orientations of the ciliate roots in the cells located around the mouth indicates that their movement should canalize fluid (and food) towards the mouth. Within the syncytium, food particles are enclosed in temporary vacuoles that move as the result of cytoplasmic currents presumably driven by microtubular motors. As digestion progresses, the food particles break up, which can take up to $24 \mathrm{~h}$. The indigestible residues then pass to the mouth and are eliminated by exocytosis.

Smith (1981) gave a more detailed ultrastructural description of the cellular organization of the convolutid digestive syncytium throughout the development from hatchling to the adult stage. He noted that the biosynthetic activity, evidenced by the amount of endoplasmic reticulum and Golgi apparatus, varies substantially during development; high in prehatchlings and low in the adults. The syncytium is filled by highly vacuolated (sizes in the range 200-400 nm) cytoplasm and several roughly spherical nuclei (around 3 um diameter). The peripheral parenchyma consists of "wrapping cells" whose processes invaginate into the syncytium. Importantly, the membranes of these wrapping cells and that of the central syncytium are not fused and specialized junctions are absent. Smith (1981) observed that the "nuclei of wrapping cells are similar to those of the central syncytium in their heterochromatin pattern and the possession of a prominent, rounded, nucleus". This structural resemblance may point towards some developmental relationship between these cells and those of the syncytium, an argument supported by ultrastructural and enzymatic data (Markosova 1976; Smith 1981) (see also the section on S. roscoffensis and Fig. 3). The wrapping cells, as the name suggests, effectively isolate the syncytium from the rest of the body. In fact, only these cells are in contact with the syncytial mass. Smith classified the wrapping cells into three types, based on their structure and position: type I, type II and type III. The three classes are present in both juveniles and adults and in very similar positions. Note that we use a different numbering here than previously used for the Diophistoporus wrapping cells (Latin instead of Arabic numbers). We do this to avoid specific statements of homology (we need more data for it). Type I cells are found in the ventral and lateral regions; type II cells cover a major proportion of the outer surface of the syncytium; while type III cells are confined to the dorsal side of the syncytium. The types are differentiated by their characteristic morphology, their vacuole content and the distribution of internal organelles:

Type I cells contain vesicles of similar size and appearance to those present within the syncytium and prompted Smith (1981) to suggest that type 1 cells may fuse with the syncytium and transfer the vesicles to it. These vesicles are, 


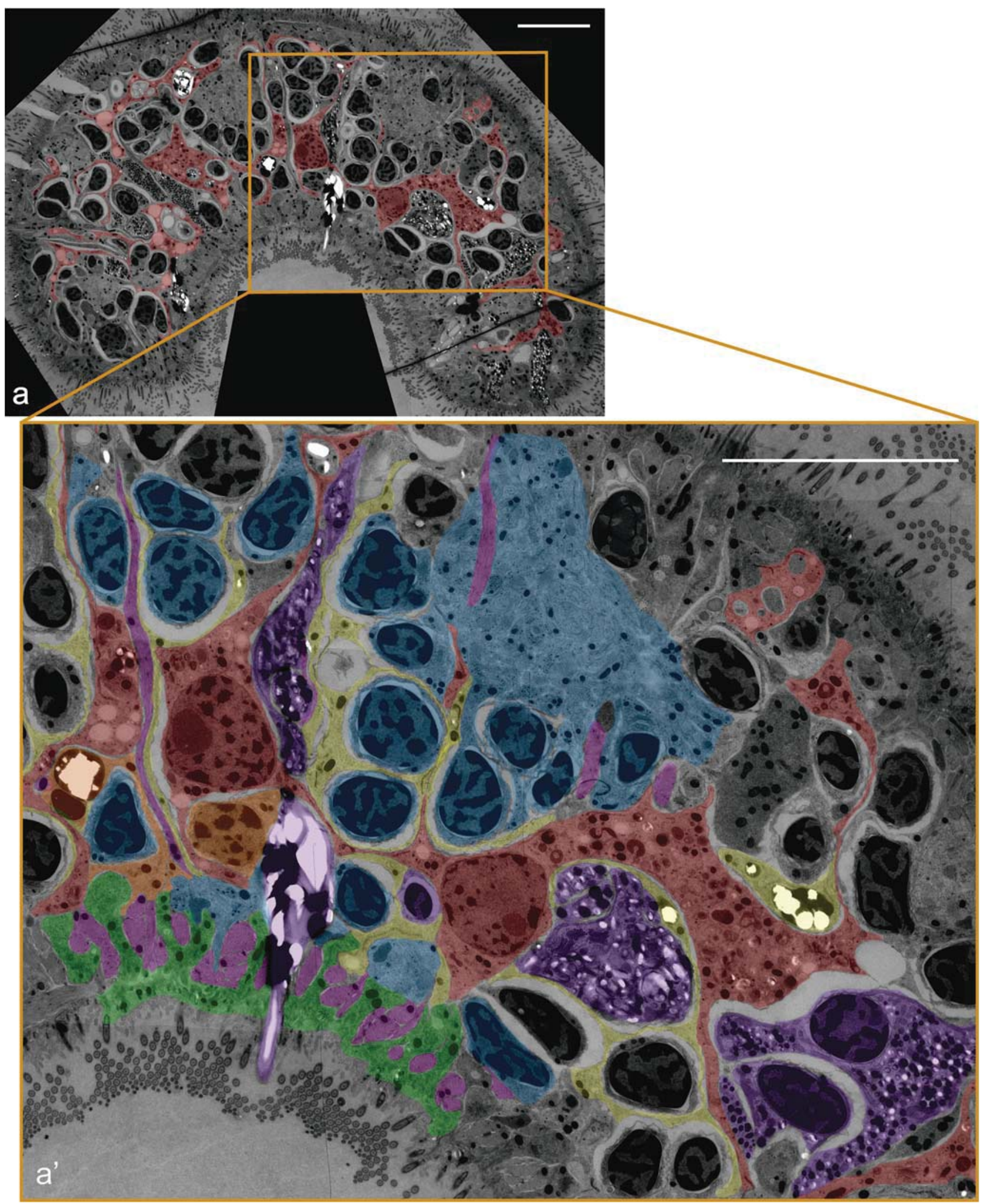

Fig. 3 TEM cross-section of a syncytium fragment of the acoel S. roscoffensis (dorsal to the top). Diagram derived from the stitching of 100 independent, high-resolution, pictures taken of the same histological section. In the first picture, we can see the whole extent of the section with the syncytium highlighted in red. In the second picture, we show the

amplification of the squared fragment. Red, digestive syncytium; Yellow, peripheral parenchymal cells/fragments; Orange, peripheral parenchymal cell and its nucleus; Pink, muscle cells; Purple, gland cells; Blue, neuronal cells; Green, epidermal cells. Scalebar: $10 \mu \mathrm{m}$ 
most probably, lysosomes, given the fact that Markosova (1976) has showed that they contain acid phosphatase and are clearly detected in active feeding animals.

Type II and III cells are probably in charge of distributing nutrients to the rest of the body but are not actively involved in the digestive process. In C. convoluta, type II cells cover most of the surface of the syncytium and bear fewer vacuoles than type I cells (Smith 1981).

The fact that the wrapping cells are the only cellular type in close contact with the syncytium and only have processes that wrap or enter the syncytium but never do so to other regions of the body, prompted Smith to suggest that wrapping cells plus the central syncytium form a "well-defined anatomical unit". The structural continuity between the wrapping cells and the syncytium and the evidence that the nuclei of the former end up within the digestive syncytium, constitutes the base for considering the syncytium plus the wrapping cells as a functional unit. This hypothesis is reinforced by the fact that digestive (or secretory) roles are also being associated with the wrapping cells. However, only in a few cases, such as in Paedomecynostomum (family Mecynostomidae), though not in Convoluta, wrapping cells have been seen containing small particles (i.e, silt), the result of phagocytic activity (Smith 1981).

Drobysheva (1986), also studying Convoluta, arrived at a description of the parenchyma that slightly differs from the one by Smith (1981). According to Drobysheva (1986), the central parenchyma is further divided into two domains; a marginal domain (along the border with the peripheral parenchyma) and a middle domain. Without further clarification, it is difficult to know if Drobyseva's marginal domain corresponds anatomically to Smith's wrapping cells and for this reason, we will not dwell further on this anatomical study. However, Drobysheva's study is relevant for a different reason. He studied the pattern of cell division within the parenchyma of two acoels, Convoluta and Oxyposthia, using thymidine autoradiography. The study showed that in Convoluta, mitotic figures were only present in the peripheral parenchyma. In Oxyposthia, Drobysheva (1986) noted the presence of labeled nuclei in the marginal but not middle, domain of the central parenchyma, which could include wrapping cells (our own interpretation). Be that as it may, what is clearly seen is that the migration (replacement) of cells in Convoluta occurs directionally from the peripheral to the central parenchyma.

\section{Some specialized systems within the Crucimusculata. Digestive syncytium enclosing cavity: Actinoposthia (Actinoposthiidae) and Oxyposthia (Convolutidae)}

Several acoel species scattered throughout the more recently diversified class Crucimusculata combine a central digestive syncytial structure with an extracellular cavity that lies within the syncytial structures. In Actinoposthia beklemischevi, a member of the Actinoposthiidae family (Fig. 2), Raikova
(1987) documented a well-developed digestive cavity limited by processes of digestive cells and when filled with small blebs of cytoplasm pinched off these processes. Active secretion of digestive enzymes occurs there. In the lateral walls of the cavity, temporary syncytial structures can be seen; these give rise, upon degeneration, to concentric layers of membranes surrounding the ingested food. These layers are likely to preserve the tissues of the animal from destruction by the digestive enzymes. The digestive cells lining the cavity (central parenchymal cells) accumulate digestive enzymes that enter in the cavity either via the membrane-bound vesicles torn from these cell projections (apocrine secretion) or through decomposition of the whole digestive cell (holocrine secretion).

Other acoels for which an extracellular cavity is combined with a digestive syncytium are Kuma flava (Haploposthiidae), Haploposthia opisthorchis (Haploposthiidae), Aphanostoma virescens (Isodiametridae) and Paedomecynostomum psammophilum (Mecynostomidae). In these species, the syncytium surrounding the large "extra-syncytial cavity" is a permanent structure (Smith 1981). A layer of wrapping cells covers the syncytium (Fig. 2).

How is the extracellular cavity formed? In the case of Oxyposthia (family Convolutidae), Mamkaev and Markosova (1982) described the syncytium as the "last stage in the irreversible degeneration of digestive cells". In this species, the digestive parenchyma consists of multifunctional cells (amoeboid phagocytes) in which intracellular digestion and biosynthesis occurs. Acid phosphatase is detected in microvesicles of the Golgi complex, lysosomes and in many vesicles within the multivesicular bodies. Oxyposthia lacks digestive glandular cells. In this species, the gut is normally cellular, composed of "amoeboid phagocytes" when it does not feed. A syncytium is formed from the digestive cells only when the prey is swallowed. This syncytium contains disintegrated cellular material and thus, formed by the degeneration of individual digestive cells. The formation of the syncytium from disintegrated cells results in the release of the digestive enzymes in the large syncytial domain, where the prey is digested. The enzymes released from the degenerating cells are dedicated to the initial treatment of large pieces of food, making it ready for the later intracellular digestion. After digestion, the syncytium disappears. This apparent peculiarity of Oxyposthia might be an adaptation to digesting large prey.

\section{One specific case: the digestive system of S. roscoffensis}

Over the last few years, we have been analyzing different aspects of the morphology and development of the acoel Symsagittifera roscoffensis, another member of the family Convolutidae, which lives in the Atlantic coast of Europe (Arboleda et al. 2018). As part of our study of the different 
tissue architectures, we generated a map of cell types within the hatchling by using the serial section TEM approach. In it, we have been looking at cells distributed over the first anterior half of the animal, all located in about 1000 different sections and covered by a total of around 100,000 different stitched images. The study follows the original (but incomplete) analysis of Bery and collaborators (Bery et al. 2010) and represents a unique opportunity to understand, both qualitatively and quantitatively, the topographic disposition of cells in any tissue. We develop in this section what we have understood and/or corroborated on the structural components in the digestive system of this acoel.

It is fair to say that there are no major changes in our view of the $S$. roscoffensis gut architecture, with respect to what other authors, including us, have published in the past. However, there are aspects that could not be firmly established because of the lack of a proper integrated view of the tissue, which is obtained through the analysis of a serial TEM-section approach. The first remarkable observation of the $S$. rocoffensis gut is certainly a syncytial structure, as shown in Fig. 3, where we can observe two of the syncytium nuclei connected through the same, branched, cytoplasm (syncytium highlighted in red). A series of consecutive sections confirm the absence of cellular membranes in the space analyzed with the rest of nuclei observed as part of the syncytium. Individual, or a few TEM sections, could not establish with certainty the syncytial nature and this was actually a reason for the old controversy generated by the observations and interpretations of Pedersen (1964), something that Mamkaev criticized early on. A big fraction of this syncytial structure is occupied by the shared cytoplasm with the presence of just a scant number of nuclei scattered within it. We did not observe any lumen.

It is quite interesting to observe that several of the peripheral cells lining the syncytium (Fig. 3, yellow) show ultrastructural features similar to those of the syncytium itself (e.g., the structure of the nuclei or the abundance of lipid bodies). This prompts us to speculate, as other authors did in the past (Smith and Tyler 1985) that peripheral cells are replenishing the syncytium, constantly dividing and fusing with the syncytium. Such a mechanism would correspond to the one proposed by Smith (1981) (summarized in Smith and Tyler 1985) who followed the development of Convoluta sp. nov. from the prehatchling stage to the adult and could see that the syncytium was renewed by the fusion of the bordering (wrapping) cells.

It is important to point out the highly branched nature of the syncytium, a feature shared with the peripheral cells that we found surrounding it. These peripheral cells form sheaths that wrap the syncytium and other cell types close to it. In addition, the syncytium itself emits large numbers of lamellar processes that interdigitate in between all cell types, including muscle, neurons, glands and epidermis. Thus, it is quite common to see muscle cells (Fig. 3, pink) in close contact with the peripheral/wrapping cells and the syncytium. In many cases, processes of peripheral cells and syncytium form a doublelayered sheath, in other cases; cells (e.g., gland cells (purple) and neurons (blue) as shown in Fig. 3) in the vicinity of the syncytium are wrapped by a single sheath formed by peripheral cells. These findings appear to differ from what has been described for other acoels (i.e., Smith 1981), where only the peripheral (wrapping) cells contribute to sheaths around other cells. However, as repeatedly commented above, it is equally possible that, in the absence of a complete series of consecutive sections covering a large part of the animal, sheathforming processes of the syncytium were mistaken for those of peripheral cells. It is of course also possible that the difference is due to the fact that we work with a different species, or a different developmental stage (hatchling, as opposed to adult).

\section{The digestive system of xenacoelomorphs lacks an enteric nervous system (ENS)}

The rather characteristic architecture of most xenacoelomorph digestive systems is complemented by another peculiar feature, namely the lack of nerve cells. This is clearly different from what is observed in Cnidaria, as well as in Protostomia and Deuterostomia. In many cnidarians, as well as essentially all bilaterian animals, there are neurons forming a nerve net (enteric nervous system; also called the stomatogastric nervous system in some clades) around the gastrodermis. The lack of an enteric nervous system in Xenacoelomorpha is, most probably, a derived condition. It is striking that this system, controlling ingestion and rhythmic peristalsis of the gut in a largely autonomous fashion in most bilaterians, has been lost in xenacoelomorphs. One might speculate that the lack of enteric neurons is the result of adaptation to meet the feeding requirements of animals with radically different lifestyles. The fact that, except in the case of xenoturbellids, a visceral muscular layer does not bind the digestive system of acoelomorphs, could explain why the enteric nervous system is dispensable. The lack of neurons associated with a visceral muscular layer may be an adaptation to a digestion that does not rely on physical movements, such as peristalsis. Alternatively, it can also be speculated that the highly developed external muscle layer, and in particular, the extremely dense array of vertical muscles, takes on the role of visceral muscles. We should end this short discussion of the ENS by pointing out the fact that an existing ultrastructural description of acoels is still fairly incomplete and a categorical denial of the presence of any kind of innervation controlling digestive processes is still unwarranted. 


\section{Phylogeny and ontogeny of the xenacoelomorph digestive system}

The interior of xenacoelomorphs is occupied by a blind gut that lacks any structurally overt subdivisions, though the analysis of molecular expression data is suggesting a rather more complex structure (Andrikou et al. n.d.), at least in the acoelomorphs. The nature of the gut varies widely and ranges from the epithelial gut of Xenoturbellida and Nemertodermatida to the syncytial form present in most acoels. The variation of architectures, as discussed above, could be summarized as follows:

(1) Xenoturbellids and nemertodermatids have an epithelial gut with an internal lumen. While most of the gastrodermal cells seem to lack cilia, Karling (1967) maintained that Nemertoderma (genus) has a partially ciliated structure, though this could be a misinterpretation of the histological images (see above "The digestive system of Nemertodermatida")

(2) Some basal acoels, like Paratomella, have a non-epithelial but cellular gut, consisting of a solid mass of mesenchymal cells. In the case of Oxyposthia (family Convolutidae), following food ingestion, the inner part of this mass undergoes "necrosis" (Mamkaev and Markosova 1982), which may be a process similar to what is considered "holocrine secretion" in other animals, where the entire gut cell (gland cell) bursts and releases its content into lumen. To be precise, Mamkaev used holocrine as: "a morphonecrotic secretion of cells which lie peripherally and release digestive enzymes" (a terminology that might not be used by others in the same context). The decomposition of the mesenchymal mass creates a cavity filled with enzymes; in it floats the prey. The prey is broken by the enzymes and absorbed (phagocytosis) by the peripheral parenchyma. Syncytial structures are transitory and would be generated during the digestion of prey.

(3) Some basal acoels (e.g., Diopisthoporidae), as well as most Convolutidae and other Crucimusculata have a permanent central syncytium. The syncytium is surrounded by peripheral, or "wrapping", cells that regenerate the syncytium and from processes involved in the distribution of nutrients (extensive wrapping around bodies of most cell types; see $S$. roscoffensis).

(4) Other, specialized cases within the Crucimusculata possess wrapping cells and a syncytium that encloses an extracellular cavity. This condition could have arisen independently multiple times.

It is important to point out that syncytial guts have recurrently evolved within the Acoela (Diophistoporidae and Convolutidae being two examples of clades distantly related).
Some authors have speculated that syncytial guts are just transitory structures (Mamkaev and Markosova 1982), present only in feeding animals (as an adaptation for digestion of big prey). This assertion has been challenged by the studies of Smith (1981) who showed that non-feeding hatchlings/ juveniles of some species have already syncytial guts. Our analysis of a freshly hatched $S$. roscoffensis agrees with the observation of Smith (1981). An alternative scenario has been proposed in which syncytial guts are an evolutionary derived condition, whereby the syncytium has formed from an epithelial gut whose cells have merged into a syncytial mass. According to this scenario, guts like the one described by Raikova (1987) for Actinoposthia beklemischevi could represent an evolutionary transition form. This possibility needs further exploration, through the characterization of gut structure in different clades and with the addition of molecular markers that could reveal commonalities in the structure or development of gut-associated cells in different acoels.

It is important to point out that, while we have gained some knowledge of ultrastructural aspects of the organization of digestive systems in many xenacoelomorph clades, what is really missing is a thorough understanding of the development of the endomesoderm and its constitutive lineages. Henry and collaborators (Henry et al. 2000), who traced the embryological history of the major lineages in the species Neochilida fusca, showed that the endomesoderm (including the peripheral and central "parenchyma") derives from both third duet macromeres. Direct observation of the morphogenesis in this species (Ramachandra et al. 2002) confirmed that a distinct inner primordium, consisting of large mesenchymal cells, gives rise to the digestive syncytium during a late embryonic stage. However, more detailed analyses are needed, in particular, studies focusing on gene expression patterns for different xenacoelomorphs. To address questions of gut phylogeny (e.g., how does a non-innervated central syncytium derive from a presumably epithelial ancestral gastrodermis with an enteric nerve net), we need to know how the digestive system is patterned by the early expression of regulatory genes. Can one recognize a gene hierarchy similar to the one in protostomes and deuterostomes and reveal associate genes with distinct cell types and digestive areas within the gut? A necessary step, which is fairly easily accomplished with modern technology, is the analysis of single-cell transcriptomes, in as many xenacoelomorph representatives as possible. Such data sets would provide us with a knowledge base of the cell types and their development, which would serve as the basis for much more educated hypotheses concerning the origin of the xenacoelomorph digestive structure and function.

Acknowledgments We would like to thank Dr. Olga Raikova (Saint Petersburg, Russia) for helping us clarifying some ultrastructural details of the Acoela that were needed for this review. Prof. Julian P.S. Smith III (Winthrop University, USA) kindly sent us a copy of his, comprehensive, $\mathrm{PhD}$ thesis on acoel digestive systems. Dr. Kennet Lundin (Gothenburg 
Natural History Museum, Sweden) was also instrumental in helping us to understand some aspects of the nemertodermatids' digestive system.

The Meara stichopi stained section was provided by Dr. John Buckland-Nicks (Antigonish, Nova Scotia, Canada). Sections of Xenoturbella bocki were obtained from Michaela Egertova and Dr. Maurice Elphick (London, UK) and processed in house.

We would like to thank the anonymous referees for helping us to improve the manuscript.

Funding V: H. would like to acknowledge the financial support provided by the NIH (NIH Grant 1RO1 R01 NS054814 to V.H.). PM and SGS would like to thank the financial support provided by the "KVA fund for internationalization and scientific renewal at the Sven Lovén Centre" that allowed them to collect Xenoturbella specimens in Sweden. In addition, SGS would like to thank the support provided by the COST SNF Grant IZCOZ0_182957.

\section{Compliance with ethical standards}

Conflict of interest The authors declare that they have no conflict of interest.

Ethical approval This article does not contain any studies with human participants performed by any of the authors.

\section{References}

Achatz JG, Martinez P (2012) The nervous system of Isodiametra pulchra (Acoela) with a discussion on the neuroanatomy of the Xenacoelomorpha and its evolutionary implications. Front Zool 9(1):27. https://doi.org/10.1186/1742-9994-9-27

Achatz JG et al (2013) The Acoela: on their kind and kinships, especially with nemertodermatids and xenoturbellids (Bilateria incertae sedis). Org Divers Evol 13(2):267-286. https://doi.org/10.1007/s13127012-0112-4

Andrikou C, Thiel D, Ruiz-Santiesteban JA, Hejnol A (n.d.) Excretion through digestive tissues predates the evolution of excretory organs. bioRxiv (136788)

Arboleda E et al (2018) An emerging system to study photosymbiosis, brain regeneration, chronobiology, and behavior: the marine Acoel Symsagittifera roscoffensis. BioEssays 40(10):e1800107. https:// doi.org/10.1002/bies.201800107

Arroyo AS et al (2016) Hidden diversity of Acoelomorpha revealed through metabarcoding. Biol Lett 12(9). https://doi.org/10.1098/ rsbl.2016.0674

Baguñà J, Riutort M (2004) The dawn of bilaterian animals: the case of acoelomorph flatworms. BioEssays 26(10):1046-1057. https://doi. org/10.1002/bies.20113.

Beltagi S, Mandura AS (1991) Hofstenia arabiensis Nov . Sp . ( Hofsteniidae ): a new species of Acoelan Turbellaria from the Red Sea north of J eddah. JKAU: Sci 3:65-90

Bery A et al (2010) Structure of the central nervous system of a juvenile acoel, Symsagittifera roscoffensis. Dev Genes Evol 220(3-4):6176. https://doi.org/10.1007/s00427-010-0328-2

Børve A, Hejnol A (2014) Development and juvenile anatomy of the nemertodermatid Meara stichopi (bock) Westblad 1949 (Acoelomorpha). Front Zool 11:50. https://doi.org/10.1186/17429994-11-50

Bourlat SJ et al (2008) Feeding ecology of Xenoturbella bocki (phylum Xenoturbellida) revealed by genetic barcoding. Mol Ecol Resour 8(1):12-22. https://doi.org/10.1111/j.1471-8286.2007.01959.x
Buckland-Nicks, J., Lundin, K. Wallberg A (2019) The sperm of Xenacoelomorpha revisited: implications for the evolution of early bilaterians. https://doi.org/10.1007/s00435-018-0425-8

Corrêa DD (1960) Two new marine Turbellaria from Florida. Bull Mar Sci Gulf Carrib 10:208-216

Crezée M, Tyler S (1976) Hesiolicium gen.N. (Turbellaria Acoela) and observations on its ultrastructure. Zool Scr 5(1-4):207-216. https:// doi.org/10.1111/j.1463-6409.1976.tb00700.x

Dorey AE (1965) 'The organization and replacement of the epidermis in acoelous turbellarians.', $Q$. J Microsc Sci 106:147-172

Drobysheva IM (1986) Physiological regeneration of the digestive parenchyma in Convoluta convoluta and Oxyposthia praedator (Turbellaria, Acoela). Hydrobiologia 132(1):189-193

Ehlers U (1992a) Dermonephridia-modified epidermal cells with a probable excretory function in Paratomella rubra (Acoela, Plathelminthes). Microfauna Mar 7:253-264

Ehlers U (1992b) On the fine structure of Paratomella rubra Rieger \&amp; Ott (Acoela) and the position of the taxon Paratomella Dörjes in a phylogenetic system of the Acoelomorpha (Plathelminthes). Microfauna Mar 7:265-293

Faubel A, Dörjes J (1978) Flagellophora apelti gen.N. sp.n.: a remarkable representative of the order Nemertodermatida (Turbellaria: Archoophora). Senckenb Marit 10:1-13

Haszprunar G (2015) Review of data for a morphological look on Xenacoelomorpha (Bilateria incertae sedis). Org Divers Evol 16(2):363-389. https://doi.org/10.1007/s13127-015-0249-z

Hejnol A (2015) Acoelomorpha and Xenoturbellida. In: Wanninger A (ed) Evolutionary developmental biology of invertebrates vol. 1 . Springer, Vienna, pp 203-214

Hejnol A (2016) Acoelomorpha. In: Structure and evolution of invertebrate nervous systems. Andreas Schmidt-Rhaesa, Steffen Harzsch, Günter Purschke. Oxford University Press, Oxford, pp 56-62

Hejnol A, Pang K (2016) Xenacoelomorpha's significance for understanding bilaterian evolution. Curr Opin Genet Dev:48-54. https:// doi.org/10.1016/j.gde.2016.05.019

Henry JQ, Martindale MQ, Boyer BC (2000) The unique developmental program of the acoel flatworm, Neochildia fusca. Dev Biol 220(2): 285-295. https://doi.org/10.1006/dbio.2000.9628

Hooge $M$ et al (2007) A revision of the systematics of panther worms (Hofstenia spp., Acoela), with notes on color variation and genetic variation within the genus. Hydrobiologia 592(1):439-454. https:// doi.org/10.1007/s10750-007-0789-0

Israelsson O (1999) New light on the enigmatic Xenoturbella (phylum uncertain): ontogeny and phylogeny. Proc R Soc B Biol Sci 266: 835. https://doi.org/10.1098/rspb.1999.0713

Israelsson O (2006) Observations on some unusual cell types in the enigmatic worm Xenoturbella (phylum uncertain). Tissue Cell 38(4): 233-242. https://doi.org/10.1016/j.tice.2006.05.002

Israelsson O (2007) Chlamydial symbionts in the enigmatic Xenoturbella (Deuterostomia). J Invertebr Pathol 96(3):213-220. https://doi.org/ 10.1016/j.jip.2007.05.002

Ivanov AV, Mamkaev YV (1977) Über die Struktur des Digestionsparenchyms bei Turbellaria Acoela. Acta Zool Fenn 154:59-61

Jennings JB (1957) Studies on feeding, digestion, and food storage in free-living flatworms (Platyhelminthes: Turbellaria). Biol Bull 112(1):63-80. https://doi.org/10.2307/1538879

Jondelius U, Wallberg A, Hooge M, Raikova OI (2011) How the worm got its pharynx: phylogeny, classification and bayesian assessment of character evolution in acoela. Syst Biol 60(6):845-871. https:// doi.org/10.1093/sysbio/syr073

Karling T (1967) Zur Frage von dem systematischen Wert der Kategorien Archoophora und Neoophora (Turbellaria). Comment Biol Soc Sci Fenn 30(3):1-11 
Karling TG (1974) On the anatomy and affinities of the turbellarian orders. In: Riser NW, Morse MP (eds) Biology of the Turbellaria. McGraw-Hill, New York, pp 1-16

Kjeldsen KU et al (2010) Two types of endosymbiotic bacteria in the enigmatic marine worm Xenoturbella bocki. Appl Environ Microbiol 76(8):2657-2662. https://doi.org/10.1128/AEM.0109209

Klima J (1967) Zur Feinstrucktur des acoelen Süsswasserturbellars Oligochoerus limnophilus (Ax \& Dörjes). Ver Naturwiss-Med Ver Innsb 55:107-124

Kozloff EN (1972) Selection of food, feeding, and physical aspects of digestion in the Acoel Turbellarian Otocelis luteola. Trans Am Microsc Soc 91(4):556-565. https://doi.org/10.2307/3225484

Lundin K (2001) Degenerating epidermal cells in Xenoturbella (phylum uncertain), Nemertodermatida and Acoela (Platyhelminthes). Belg J Zool 131(1):153-157

Lundin K, Hendelberg J (1996) Degenerating bodies ("pulsatile bodies") in the epidermis of Meara stichopi (Platyhelminthes, Nemertodermatida). Zoomorphology 116:1-5

Mamkaev YV (1967) 'Ocherki po morfologii beskishechnykh turbellarij.', Trudy Zool. Inst AN SSSR Leningrad 44:26-108

Mamkaev YV (1986) Initial morphological diversity as a criterion in deciphering turbellarian phylogeny. Hydrobiologia 132:31-32

Mamkaev YV, Markosova TG (1982) Peculiarities of feeding and digestion of Oxyposthia praedator (Turbellaria, Acoela). Pacific Sci Cong Proceedings 14:97-102

Mamkaev IV, Seravin LN (1963) Feeding of the acoelous turbellarian Convoluta convoluta (Abildgaard). J Zool Zh 47:197-205

Markosova TG (1976) Acid phosphatase activity during digestion in the anintestinal Turbellaria Convoluta convoluta. Zh Evol Biokhim Fiziol 12:183-184

Martinez P, Hartenstein V, Sprecher SG (2017) Xenacoelomorpha nervous systems. In: Sherman SM (ed) Oxford Encyclopaedia of neurosciences. Oxford University Press, Oxford

Meyer-Wachsmuth I, Raikova OI, Jondelius U (2013) The muscular system of Nemertoderma westbladi and Meara stichopi (Nemertodermatida, Acoelomorpha). Zoomorphology 132(3):239252. https://doi.org/10.1007/s00435-013-0191-6

Meyer-Wachsmuth I, Curini-Galletti M, Jondelius U (2014) Hypercryptic marine meiofauna: species complexes in Nemertodermatida. PLoS One 9(9):e107688. https://doi.org/10. 1371/journal.pone. 0107688

Papi F (1957) Sopra un nuovo Turbellario arcooforo di particolare significato filetico e sulla posizione della fam. Hofsteniidae nel sistema dei Turballari. Pubbl Stn Zool Napoli 30:132-148

Pedersen KJ (1964) 'the cellular organization of Convoluta convoluta, an acoels turbellarian: a cytological, histochemical and fine structural study'. Zeitschrift für Zellforschung und mikroskopische Anatomie (Vienna Austria, 1948) 64:655-687

Perea-Atienza E et al (2013) Posterior regeneration in Isodiametra pulchra (Acoela, Acoelomorpha). Front Zool 10(1):64. https://doi. org/10.1186/1742-9994-10-64

Philippe $\mathrm{H}$ et al (2011) Acoelomorph flatworms are deuterostomes related to Xenoturbella. Nature 470(7333):255-258. https://doi.org/10. 1038/nature09676

Raikova OI (1987) Ultrastructural organization of the digestive system of the acoel turbellarian Actinoposthia beklemishevi Mamkaev. [in Russian]. Tr Zool Inst Nauk USSR 167:72-78

Raikova OI et al (2000) An immunocytochemical and ultrastructural study of the nervous and muscular systems of Xenoturbella westbladi (Bilateria inc. sed.). Zoomorphology. 120(2):107-118. https://doi.org/10.1007/s004350000028

Ramachandra NB et al (2002) Embryonic development in the primitive bilaterian Neochildia fusca: normal morphogenesis and isolation of POU genes Brn-1 and Brn-3. Dev Genes Evol 212(2):55-69. https:// doi.org/10.1007/s00427-001-0207-y

Riedl R (1954) Neue Turbellarien aus dem mediterranen Felslittoral. Ergebnisse der "'Unterwasser-Expedition Austria 1948- 1949". Zool Jahrb Syst (Wien) 82:157-244

Riser NW (1987) Nemertinoides elongatus gen.N., sp.n. (Turbellaria: Nemertodermatida) from coarse sand beaches of the western North Atlantic. Proc Helmintol Soc Wash 54(1):60-67

Rouse GW et al (2016) New deep-sea species of Xenoturbella and the position of Xenacoelomorpha. Nature. 530(7588):94-97. https:// doi.org/10.1038/nature16545

Semmler H, Bailly X, Wanninger A (2008) Myogenesis in the basal bilaterian Symsagittifera roscoffensis (Acoela). Front Zool 5:1-15. https://doi.org/10.1186/1742-9994-5-14

Sikes JM, Bely AE (2008) Radical modification of the A-P axis and the evolution of asexual reproduction in Convolutriloba acoels. Evol Dev 10(5):619-631. https://doi.org/10.1111/j.1525-142X.2008. 00276.x

Smith JPS (1981) Fine-structural anatomy of the parenchyma in the Acoela and Nemertodermatida (Turbellaria). PhD. Thesis. North Carolina, Chapel Hill

Smith JPS III (1981) Fine-structural observations on the central parenchyma in Convoluta sp. Hydrobiologia 84:259-265

Smith J III, Tyler S (1985) The acoel turbellarians: kingpins of metazoan evolution or a specialized offshoot? In: Conway Morris S, George JD, Gibson R, Platt HM (eds) The origins and relationships of lower invertebrates. Clarendon Press, Oxford, p 123142

Srivastava $\mathrm{M}$ et al (2014) Whole-body acoel regeneration is controlled by Wnt and bmp-Admp signaling. Curr Biol 24(10):1107-1113. https://doi.org/10.1016/j.cub.2014.03.042

Steinböck O (1930) Ergebnisse einer von E. Reisinger \&amp; 0. Steinbock mit Hilfe des Rask- 0rsted Fonds durchgefuhrten Reise in Gronland 1926.2. Nemertoderma buthycola nov. gen. nov. spec., eine eigenartige Turbellarie aus der Tiefe der Diskobay; nebst einem Beitrag zur Kenntnis des Nemertinenepithels. Vidensk Medd Dansk Nuturhist Foren 90:47-84

Sterrer W (1998) New and known Nemertodermatida (PlatyhelminthesAcoelomorpha): a revision. Belgian J Zool 128(1):55-92

Todt C (2009) Structure and evolution of the pharynx simplex in acoel flatworms (Acoela). J Morphol 270(3):271-290. https://doi.org/10. 1002/jmor. 10682

Tyler S, Rieger RM (1977) Ultrastructural evidence for the systematic position of the Nemertodermatida (Turbellaria). Acta Zool Fennica 54:193-207

Westblad E (1940) Studien über skandinavische Turbellaria Acoela. Arkiv för Zoologi 32A(20):1-28

Westblad E (1949a) On Meara stichopi (Bock) Westblad, a new representative of Turbellaria Archoophora. Ark Zool, Ser 2 1(5):43-57

Westblad E (1949b) Xenoturbella bocki n.g., n. sp., a peculiar, primitive turbellarian type. Ark Zool 1:3-29

Publisher's note Springer Nature remains neutral with regard to jurisdictional claims in published maps and institutional affiliations. 